\title{
Decreases in TGF- $\beta 1$ and PDGF levels are associated with echocardiographic changes during adjuvant radiotherapy for breast cancer
}

Hanna Aula ${ }^{1,2^{*}} \mathbb{D}$, Tanja Skyttä ${ }^{1,2}$, Suvi Tuohinen ${ }^{1,3,4}$, Tiina Luukkaala ${ }^{5,6}$, Mari Hämäläinen ${ }^{7}$, Vesa Virtanen ${ }^{1,3}$, Pekka Raatikainen ${ }^{4}$, Eeva Moilanen ${ }^{7}$ and Pirkko-Liisa Kellokumpu-Lehtinen ${ }^{1,2}$

\begin{abstract}
Background: Radiation-induced heart disease is mainly caused by activation of the fibrotic process. Transforming growth factor-beta 1 (TGF- $\beta 1$ ) and platelet-derived growth factor (PDGF) are pro-fibrotic mediators. The aim of our study was to evaluate the behavior of TGF- $\beta 1$ and PDGF during adjuvant radiotherapy (RT) for breast cancer and the association of these cytokines with echocardiographic changes.

Methods: Our study included 73 women with early-stage breast cancer or ductal carcinoma in situ (DCIS) receiving post-operative RT but not chemotherapy. TGF- $\beta 1$ and PDGF levels in serum samples taken before and on the last day of RT were measured by an enzyme-linked immunosorbent assay. Echocardiography was also performed at same time points. Patients were grouped according to $\mathrm{a} \geq 15 \%$ worsening in tricuspid annular plane systolic excursion (TAPSE) and pericardium calibrated integrated backscatter (cIBS).

Results: In all patients, the median TGF- $\beta 1$ decreased from 25.0 (IQR 21.1-30.3) ng/ml to 23.6 (IQR 19.6-26.8) ng/ml $(p=0.003)$, and the median PDGF decreased from 18.0 (IQR 13.7-22.7) $\mathrm{ng} / \mathrm{ml}$ to 15.6 (IQR 12.7-19.5) $\mathrm{ng} / \mathrm{ml}(p<0.001)$. The baseline TGF- $\beta 1,30.7$ (IQR 26.0-35.9) ng/I vs. 23.4 (IQR 20.1-27.3) ng/I ( $p<0.001$ ), and PDGF, 21.5. (IQR 15.7-31.2) ng/l vs. 16.9. (IQR 13.0-21.2) $\mathrm{ng} / \mathrm{ml}$, were higher in patients with a $\geq 15 \%$ decrease in TAPSE than in patients with $a<15 \%$ decrease. In patients with $a \geq 15 \%$ decrease in TAPSE, the median TGF- $\beta 1$ decreased to 24.7 (IQR 20.0-29.8) ng/ml $(p<0$. 001), and the median PDGF decreased to 16.7 (IQR 12.9-20.9) $\mathrm{ng} / \mathrm{ml}(p<0.001)$. The patients with $\mathrm{a}<15 \%$ decrease had stable TGF- $\beta 1$ ( $p=0.104$ ), but PDGF decreased to 15.1 (IQR 12.5-18.6), $p=0.005$. The patients with $a \geq 15 \%$ increase in CIBS exhibited a decrease in TGF- $\beta 1$ from 26.0 (IQR 21.7-29.7) to 22.5 (IQR 16.6.-26.7) $\mathrm{ng} / \mathrm{ml}, p<0.001$, and a decrease in PDGF from 19.8 (IQR 14.6-25.9) to 15.7 (IQR 12.8-20.2) ng/ml, $p<0.001$. In patients with a $<15 \%$ increase, TGF- $\beta 1$ and PDGF did not change significantly, $p=0.149$ and $p=0.053$, respectively.

Conclusion: We observed a decrease in TGF- $\beta 1$ and PDGF levels during adjuvant RT for breast cancer. Echocardiographic changes, namely, in TAPSE and CIBS, were associated with a greater decrease in TGF- $\beta 1$ and PDGF levels. Longer followup times will show whether these changes observed during RT translate into increased cardiovascular morbidity.
\end{abstract}

Keywords: Cardiotoxicity, Breast cancer, Radiotherapy, Transforming growth factor beta-1, Platelet-derived growth factor, Echocardiography

\footnotetext{
* Correspondence: hanna.aula@uta.fi

${ }^{1}$ Faculty of Medicine and Life Sciences, University of Tampere, PO Box 100,

33014 Tampere, Finland

2Department of Oncology, Tampere University Hospital, PO Box 2000, 33521

Tampere, Finland

Full list of author information is available at the end of the article
}

(c) The Author(s). 2018 Open Access This article is distributed under the terms of the Creative Commons Attribution 4.0 International License (http://creativecommons.org/licenses/by/4.0/), which permits unrestricted use, distribution, and reproduction in any medium, provided you give appropriate credit to the original author(s) and the source, provide a link to the Creative Commons license, and indicate if changes were made. The Creative Commons Public Domain Dedication waiver (http://creativecommons.org/publicdomain/zero/1.0/) applies to the data made available in this article, unless otherwise stated. 


\section{Background}

Late adverse effects of radiotherapy (RT), including radiation-induced heart disease, are mostly caused by fibrotic processes and take years to manifest [1]. Although the relationship between fibrosis and early inflammatory responses to microvascular damage caused by radiation is still unclear, it has been shown that pro-fibrotic mediators, including the fibroblast activating cytokines transforming growth factor-beta 1 (TGF- $\beta 1$ ) and platelet derived growth factor (PDGF), are released by inflammatory, endothelial and epithelial cells [2]. Increased expression of TGF- $\beta 1$ and PDGF in response to irradiation has been reported in animal and in vitro studies [3], but evidence describing the behavior of circulating TGF- $\beta 1$ and PDGF in humans is varying [4-6].

High plasma or serum levels of TGF- $\beta 1$ before RT have been associated with fibrosis of the breast $[4,5]$. Regardless of whether patients received intra-operative RT or not, TGF- $\beta 1$ concentrations in wound fluid were similar $24 \mathrm{~h}$ after surgery [7]. The relationship between TGF- $\beta 1$ and RT has been most extensively studied in lung cancer patients. A meta-analysis concluded that the risk of radiation pneumonitis was increased in lung cancer patients receiving RT with a post-RT/pre-RT TGF$\beta 1$ ratio $\geq 1$ [6]. TGF- $\beta 1$ expression is also induced after a myocardial infarction (MI), but the exact role of TGF- $\beta 1$ in MI remains elusive [3].

Increased PDGF levels are linked to the development of fibrosis, and PDGF also acts as a pro-angiogenic mediator [8]. In one study, serum PDGF levels declined after RT of non-Hodgkin lymphoma with varying target sites [9], and in another study, serum PDGF levels did not change after chemotherapy and mediastinal RT for Hodgkin's lymphoma [10]. In animal studies, inhibition of PDGF or both TGF- $\beta 1$ and PDGF during RT attenuated the development of pulmonary fibrosis [11, 12]. To our knowledge, PDGF has not been previously studied in relation to breast cancer $\mathrm{RT}$.

The aim of our study was to evaluate the behavior of serum TGF- $\beta 1$ and PDGF during adjuvant RT for early breast cancer and to find associations with changes in echocardiographic parameters.

\section{Materials and methods}

\section{Patients}

This observational, prospective, single-center study included 73 women with early stage breast cancer or ductal carcinoma in situ (DCIS). All patients received postoperative RT after breast conserving surgery $(n=72)$ or mastectomy $(n=1)$, but did not receive chemotherapy. The patient characteristics of the study population are shown in Table 1. The inclusion and exclusion criteria have been previously described [13]. The Tampere University hospital ethics committee approved the
Table 1 Patient characteristics $(n=73)$

\begin{tabular}{lll}
\hline Age, Md (IQR; range) & 64 & $(58-66 ; 49-79)$ \\
BMI, Md (IQR; range) & 26.3 & $(24.2-29.9 ; 20-41), n=69$ \\
Left-sided BC, $n$ (\%) & 50 & $(68.5)$ \\
Al use, n (\%) & 26 & $(35.6)$ \\
Tamoxifen use, $n(\%)$ & 6 & $(8.2)$ \\
ACE or ARB use, $n(\%)$ & 22 & $(30.1)$ \\
ASA use, $n$ (\%) & 8 & $(11.0)$ \\
Beta-blocker use, $n(\%)$ & 12 & $(16.4)$ \\
Statin use, $n(\%)$ & 15 & $(20.5)$ \\
CAD, $n(\%)$ & 3 & $(4.1)$ \\
Diabetes, $n(\%)$ & 6 & $(8.2), n=69$ \\
Hypertension, $n(\%)$ & 30 & $(41.1)$ \\
Hypothyroidism, $n(\%)$ & 12 & $(16.4)$ \\
Smoking, $n(\%)$ & 8 & $(11)$
\end{tabular}

$M d$ median, $I Q R$ interquartile range, $B M I$ body mass index, $B C$ breast cancer, $A l$ aromatase inhibitor, $A C E$ angiotensin converting enzyme inhibitor, $A R B$ angiotensin II receptor blocker, ASA low dose acetylsalicylic acid, CAD coronary artery disease, Diabetes use of diabetes medication

study (R10160), and informed consent was obtained from all participants.

\section{Radiotherapy}

The RT protocol has been previously described in detail [14]. Patients received either 50 Gy in 2 Gy fractions or 42.56 Gy in 2.66 Gy fractions. The planning target volume (PTV) was the remaining breast with margins for patients with breast conserving surgery and the chest wall with margins for the post-mastectomy patient. Two patients had positive axillary nodes, and the PTV included axillary and supraclavicular areas.

\section{Serum biomarker analysis}

Serum samples were drawn before RT and on the last day of RT, and they were stored at $-80{ }^{\circ} \mathrm{C}$ until analysis. TGF- $\beta 1$ and PDGF-AB concentrations were determined with an enzyme-linked immunosorbent assay using the reagents from R\&D Systems Europe Ltd. (Abingdon, UK). The detection limit and the inter-assay coefficient of variation were $7.8 \mathrm{pg} / \mathrm{ml}$ and $5.4 \%$ for TGF-b1 and $3.9 \mathrm{pg} / \mathrm{ml}$ and $4.6 \%$ for PDGF-AB, respectively.

\section{Echocardiographic examination}

Echocardiographic examinations were performed by a single cardiologist (ST) before and at the end of RT. A commercially available ultrasound machine (Philips iE33 ultrasound system; Philips, Bothell, WA, USA) and a 1-5 $\mathrm{MHz}$ matrix-array X5-1 transducer were used to perform the examination, as previously described [13], in a standardized manner following current guidelines [15-18]. The patients were divided 
into two groups, one with $a \geq 15 \%$ decline and the other with $\mathrm{a}<15 \%$ decline in tricuspid annular plane systolic excursion (TAPSE), as we earlier reported marked changes in these two parameters $[13,19]$. The decline was chosen to represent an approximately 4- $\mathrm{mm}$ decrease in TAPSE, which can be considered a clinically meaningful change as in patients with pulmonary hypertension with every $1-\mathrm{mm}$ decrease in TAPSE, risk of death was increased by $17 \%$ [20]. Also, in our earlier study the significant average reduction of TAPSE was $2.1 \pm 3.2 \mathrm{~mm}$ and TAPSE decreased by $4 \mathrm{~mm}$ in $39 \%$ of patients [19]. Similarly, a $\geq 15 \%$ increase and $\mathrm{a}<15 \%$ increase in the pericardium calibrated integrated backscatter (cIBS) were used to categorize patients into two groups. As the magnitude of a clinically meaningful change is not known for cIBS, a $15 \%$ cutoff was used to keep the change similar to the change in TAPSE.

\section{Statistical analysis}

As the distribution of all continuous variables was skewed, medians and interquartile ranges were calculated. The Wilcoxon signed-rank test was utilized to test for changes in the biomarkers and the echocardiographic parameters from before to after RT. To test the linear relationships among the biomarkers, Spearman's correlation was used. The patients were divided into two groups for further analysis according to a $15 \%$ change in TAPSE or cIBS as described above. To test for differences in patient characteristics, biomarker levels and radiation doses between the described groups, Fisher's exact test for categorical variables, and the Mann-Whitney U-test for continuous variables were used. Multivariable logistic regression was used to test the change in TGF- $\beta 1$ or PDGF and the change in TAPSE and cIBS using age, use of hypertension medication and mean heart dose as predictors. IBM SPSS statistics for Windows (version 23, IBM Corp., Armonk, NY, USA) was used for all statistical analysis. $P$-values less than 0.05 were considered statistically significant.

\section{Results}

\section{TGF- $\beta 1$ and PDGF}

The TGF- $\beta 1$ and PDGF levels of all 73 patients were measured before and after RT. In these patients, the median (Interquartile Range; IQR) TGF- $\beta 1$ levels decreased from 25.0 (IQR 21.1-30.3) ng/ml before RT to 23.6 (IQR 19.6-26.8) $\mathrm{ng} / \mathrm{ml}$ after RT, $p=0.003$ (Fig. 1). Similarly, the median PDGF levels decreased from 18.0 (IQR 13.722.7) $\mathrm{ng} / \mathrm{ml}$ before $\mathrm{RT}$ to 15.6 (IQR $12.7-19.5) \mathrm{ng} / \mathrm{ml}$ after RT, $p<0.001$ (Fig. 1). TGF- $\beta 1$ and PDGF exhibited a strong correlation before RT (Spearman's rho $=0.802$ ) and after RT $(r h o=0.817)$. The change in TGF- $\beta 1$ also correlated with the change in PDGF (rho $=0.817$ ) (Fig. 2). There was no significant correlation between change in TGF- $\beta 1$ or PDGF and the time from surgery to RT (Additional file 1: Table S1) or radiation doses to the heart (Additional file 2: Table S2). Median time from surgery to start of RT was 56.0 (IQR 49.0-64.5) days.

\section{Transforming growth factor-beta 1, platelet-derived growth factor and cardiac function TGF- $\beta 1$ and PDGF levels and changes in TAPSE}

Sixty-six of the 73 (90\%) patients had echocardiography completed before and after RT. TAPSE declined by $\geq 15 \%$ in 20 patients and by $<15 \%$ in 46 patients. In the 20 patients with $\mathrm{a} \geq 15 \%$ TAPSE decline, TAPSE was 25.0 (IQR 23.3-30.0) $\mathrm{mm}$ before RT and 20.5 (IQR 18.0-23.0) $\mathrm{mm}$ after RT, $p<0.001$. However, in the 46 patients with $\mathrm{a}<15 \%$ decline, the median TAPSE was stable with 22.5 (IQR 20.0-26.0) $\mathrm{mm}$ and 22.0 (IQR $19.0-25.3) \mathrm{mm}(p=0.298)$ before and after RT, respectively. The baseline TAPSE was significantly higher in the group with $\mathrm{a} \geq 15 \%$ TAPSE decline than in the group with a $<15 \%$ decline, $p=0.021$. The groups were similar in body mass index (BMI), age, smoking status, proportion of left-sided breast cancer, coronary artery disease, hypertension, and use of aromatase inhibitors (AI), tamoxifen, acetylsalicylic acid (ASA), statins, levothyroxine, diabetes medication, angiotensin converting enzyme
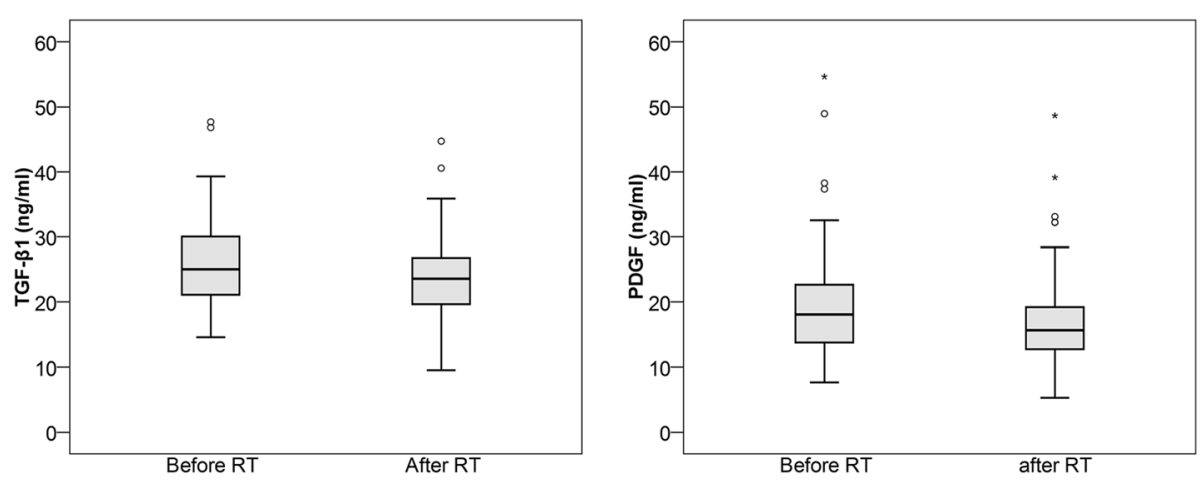

Fig. 1 TGF- $\beta 1$ and PDGF levels decreased significantly during RT, $p=0.003$ and $p<0.001$, respectively 


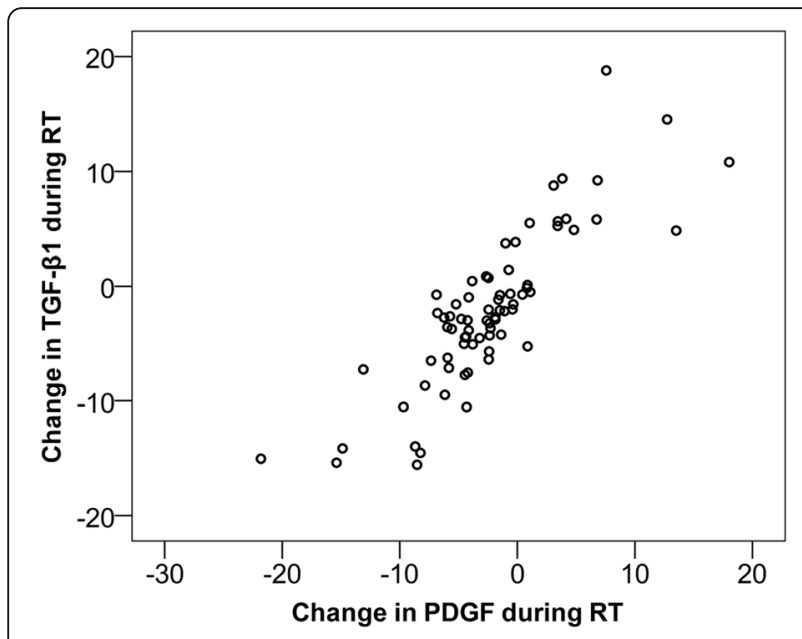

Fig. 2 Correlation of the changes in TGF- $\beta 1$ and PDGF levels during RT (Spearman's rho $=0.817$ )

(ACE) inhibitors or angiotensin reseptor blockers (ARB) and $\beta$-blockers (Additional file 3: Table S3).

In the patients with $\mathrm{a} \geq 15 \%$ decline in TAPSE, the median TGF- $\beta 1$ level decreased from 30.7 (IQR 26.0-35.9) $\mathrm{ng} / \mathrm{ml}$ before RT to 24.7 (IQR 20.0-29.8) $\mathrm{ng} / \mathrm{ml}$ after RT, $p<0.001$ (Fig. 3). TGF- $\beta 1$ remained stable in patients with $\mathrm{a}<15 \%$ decline in TAPSE, with a median TGF- $\beta 1$ of 23.4 (IQR 20.1-27.3) $\mathrm{ng} / \mathrm{ml}$ before RT and 22.6 (IQR 19.025.6) $\mathrm{ng} / \mathrm{ml}$ after RT, $p=0.104$. The baseline TGF- $\beta 1$ level was also significantly higher, $p<0.001$, in those with $\mathrm{a} \geq$ $15 \%$ TAPSE decline than in those without. There was no correlation between change in TGF- $\beta 1$ and the change in TAPSE (Additional file 4: Table S4). In a multivariable logistic regression analysis the change in TGF- $\beta 1$ remained significant, OR 0.85 (95\% CI 0.75-0.96) when age, hypertension and mean heart dose were included in the model to test variables associated with $\geq 15 \%$ and $<15 \%$ decline in TAPSE (Additional file 5: Table S5).
PDGF levels decreased significantly in both groups. In patients with $\mathrm{a} \geq 15 \%$ decline in TAPSE, PDGF levels decreased from a median of 21.5 (IQR $15.7-31.2) \mathrm{ng} / \mathrm{ml}$ before RT to a median of 16.7 (IQR 12.9-20.9) ng/ml after RT, $p<0.001$. In patients with $\mathrm{a}<15 \%$ decline, PDGF levels decreased from a median of 16.9 (IQR 13.0-21.2) $\mathrm{ng} / \mathrm{ml}$ before RT to a median of 15.1 (IQR 12.5-18.6) $\mathrm{ng} /$ $\mathrm{ml}$ after RT, $p=0.005$ (Fig. 3). In addition, the baseline PDGF level was significantly higher, $p=0.020$, in patients with $\mathrm{a} \geq 15 \%$ decline than in those with a $<15 \%$ decline. The change in PDGF did not correlate with the change in TAPSE (Additional file 4: Table S4). In a multivariable logistic regression analysis the change in PDGF remained significant, OR 0.85 (95\% CI 0.75-0.97) when age, hypertension and mean heart dose were included in the model (Additional file 6: Table S6).There was no difference in radiation doses to the heart between the groups with $\geq 15 \%$ or $<15 \%$ decline in TAPSE (Table 2).

Fifty patients had left-sided breast cancer. TGF- $\beta 1$ and PDGF behavior was similar in the left-sided patients as described above for the whole group. During RT, TGF- $\beta 1$ levels decreased from 24.1 (IQR 20.9-29.8) ng/ $\mathrm{ml}$ to 23.4 (IQR 19.4-26.9) ng/ml, $p=0.025$, and PDGF levels decreased from 17.6 (IQR 13.4-22.8) $\mathrm{ng} / \mathrm{ml}$ to 15.3 (IQR $12.7-19.8$ ) $\mathrm{ng} / \mathrm{ml}, p=0.001$. When the patients with left-sided breast cancer were grouped according to the $\geq 15 \%$ or $<15 \%$ decline in TAPSE, the mean radiation dose to the heart was higher in the group with $\mathrm{a} \geq 15 \%$ decline than in those with $\mathrm{a}<$ 15\% decline, with 3.9 (IQR 3.2-4.3) Gy and 2.2 (IQR 1.6-3.7) Gy received, respectively, $p=0.024$. Similarly, the mean doses to the left descending coronary artery (LAD), 1.1 (IQR 0.4-1.5) Gy vs. 0.7 (IQR 0.4$0.9)$ Gy $(p=0.006)$, and the left ventricle, 7.0 (IQR $4.2-8.0)$ Gy vs. 3.8 (IQR 2.1-5.6) Gy $(p=0.005)$, were significantly higher in the $\geq 15 \%$ group compared to the $<15 \%$ group.
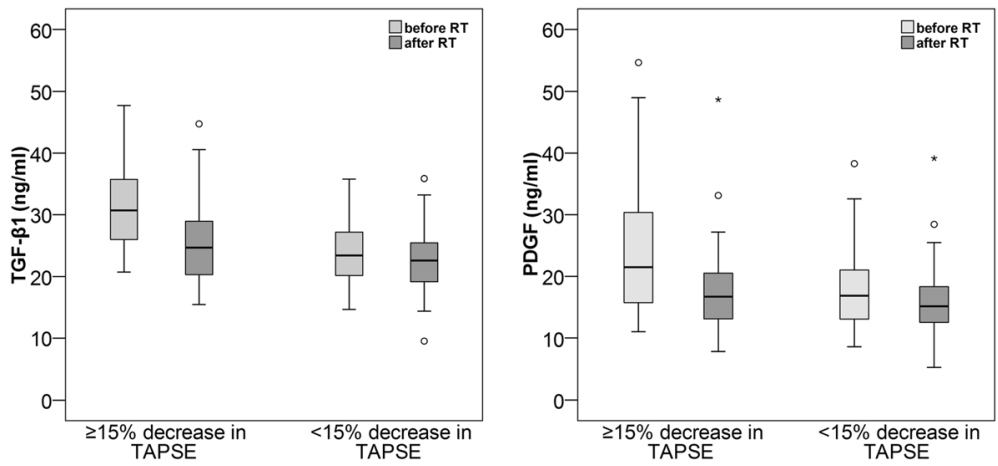

Fig. 3 Baseline TGF- $\beta 1$ and PDGF levels were higher, $p<0.001$ and $p=0.020$, respectively, and both decreased significantly, $p<0.001$, in patients with $\mathrm{a} \geq 15 \%$ decrease in TAPSE compared with patients with $\mathrm{a}<15 \%$ decrease in TAPSE. TGF- $\beta 1$ levels were stable, but PDGF levels decreased significantly, $p=0.005$, in patients with $a<15 \%$ decrease in TAPSE 
Table 2 Radiation doses according to TAPSE decline

\begin{tabular}{|c|c|c|c|}
\hline & $\geq 15 \%$ decrease in TAPSE $(n=20)$ & $<15 \%$ decrease in TAPSE $(n=46)$ & \\
\hline & $\mathrm{Md}(\mathrm{IQR})$ & $\mathrm{Md}(\mathrm{IQR})$ & p \\
\hline \multicolumn{4}{|l|}{ Heart } \\
\hline Dmean (Gy) & $3.39(0.8-4.2)$ & $1.8(0.8-3.5)$ & 0.343 \\
\hline Dmax (Gy) & $46.1(5.3-49.0)$ & $45.9(11.8-47.5)$ & 0.676 \\
\hline V45 (\%) & $0.2(0-1.3)$ & $0.1(0-0.7)$ & 0.630 \\
\hline V20 (\%) & $4.3(0-5.2)$ & $1.4(0-4.8)$ & 0.330 \\
\hline \multicolumn{4}{|l|}{ LAD } \\
\hline Dmean (Gy) & $23.7(0.3-28.5)$ & $10.3(2.3-23.5)$ & 0.414 \\
\hline Dmax (Gy) & $44.1(0.7-48.1)$ & $40.8(5.0-46.1)$ & 0.460 \\
\hline V45 (\%) & $0(0-5.2)$ & $0(0-7.3)$ & 0.663 \\
\hline V20 (\%) & $43.6(0-67.6)$ & $19.7(0-54.9)$ & 0.193 \\
\hline \multicolumn{4}{|l|}{ Left ventricle } \\
\hline Dmean (Gy) & $4.6(0.2-7.2)$ & $2.7(1.2-5.5)$ & 0.273 \\
\hline Dmax (Gy) & $44.6(0.8-47.6)$ & $44.1(5.0-46.7)$ & 0.691 \\
\hline V45 (\%) & $0.1(0-2.0)$ & $0(0-0.4)$ & 0.360 \\
\hline V20 (\%) & $6.0(0-11.7)$ & $1.7(0-7.8)$ & 0.192 \\
\hline V10 (\%) & $8.8(0-15.1)$ & $3.4(0-11.0)$ & 0.150 \\
\hline \multicolumn{4}{|l|}{ Right ventricle } \\
\hline Dmean (Gy) & $2.0(0.8-7.2)$ & $1.6(0.9-2.9)$ & 0.692 \\
\hline Dmax (Gy) & $27.6(3.1-43.4)$ & $21.3(3.3-42.8)$ & 0.988 \\
\hline V45 (\%) & $0(0-0)$ & $0(0-0)$ & 0.925 \\
\hline V20 (\%) & $0.1(0-1.3)$ & $0(0-1.3)$ & 0.848 \\
\hline V10 (\%) & $0.7(0-3.6)$ & $0.1(0-3.8)$ & 0.714 \\
\hline \multicolumn{4}{|l|}{ Ipsilateral lung } \\
\hline Dmean (Gy) & $8.1(6.4-9.1)$ & $7.7(6.2-9.0)$ & 0.484 \\
\hline Dmax (Gy) & $49.2(46.2-52.7)$ & $48.5(47.1-51.6)$ & 0.994 \\
\hline
\end{tabular}

$M d$ median, IQR interquartile range, Dmean mean radiation dose to the structure, Dmax maximum radiation dose within the structure, $V 45$ percentage of the structure volume receiving 45 Gy of radiation, V20 percentage of the structure volume receiving 20 Gy of radiation, V10 percentage of the structure volume receiving $10 \mathrm{~Gy}$ of radiation, $L A D$ left anterior descending coronary artery

\section{TGF- $\beta 1$, PDGF and change in CIBS}

Sixty-four of the 73 (88\%) patients had cIBS measured by echocardiography. Twenty-nine patients had $\mathrm{a} \geq$ $15 \%$ increase in cIBS, from a median of -19.8 (IQR -22.6- -16.6) dB before RT to a median of - 13.3 (IQR -15.3- -9.5) dB after RT, $p<0.001$. The group of $35 \mathrm{pa}-$ tients with $\mathrm{a}<15 \%$ increase in cIBS had a significant decrease in cIBS from - 17.1 (IQR -21.5- -14.6) $d B$ before RT to -18.3 (IQR -24.0- -16.7) dB after RT, $p=0.033$. The baseline cIBS values between the groups did not differ significantly, $p=0.257$. Furthermore, the groups had similar baseline characteristics (Additional file 7: Table S7). There was a tendency for patients with $\mathrm{a} \geq 15 \%$ increase to be older than those with a $<15 \%$ increase, 65 (IQR 59.5-69) years old and 62 (IQR 58-66) years old, respectively ( $p=$ $0.079)$. Additionally, smokers tended to more likely have $\mathrm{a}<15 \%$ increase in cIBS $(p=0.063)$.
In patients with $\mathrm{a} \geq 15 \%$ increase in $\mathrm{CIBS}$, the median TGF- $\beta 1$ level decreased significantly from 26.0 (IQR 21.7-29.7) $\mathrm{ng} / \mathrm{ml}$ before RT to $22.5(16.6-26.7) \mathrm{ng} / \mathrm{ml}$ after RT $(p<0.001)$ (Fig. 4). TGF- $\beta 1$ remained stable in patients with $\mathrm{a}<15 \%$ increase in cIBS, with a median TGF- $\beta 1$ level of 24.0 (IQR 20.7-31.4) $\mathrm{ng} / \mathrm{ml}$ and 24.1 (IQR $21.1-22.5) \mathrm{ng} / \mathrm{ml}$ before and after RT, respectively $(p=0.149)$. The baseline TGF- $\beta 1$ levels were similar in both groups, $p=0.518$. There was no correlation between the change in TGF- $\beta 1$ and the change in cIBS (Additional file 4: Table S4). In a multivariable logistic regression analysis the change in TGF- $\beta 1$ remained borderline significant, OR 0.91 (95\% CI $0.82-1.00$ ) when age, hypertension and mean heart dose were included in the model (Additional file 5: Table S5).

In addition to declining TGF $\beta-1$ levels, a significant decrease in PDGF levels was observed from 19.8 (IQR 14.6-25.9) $\mathrm{ng} / \mathrm{ml}$ before RT to 15.7 (IQR 12.8-20.2) $\mathrm{ng} /$ 

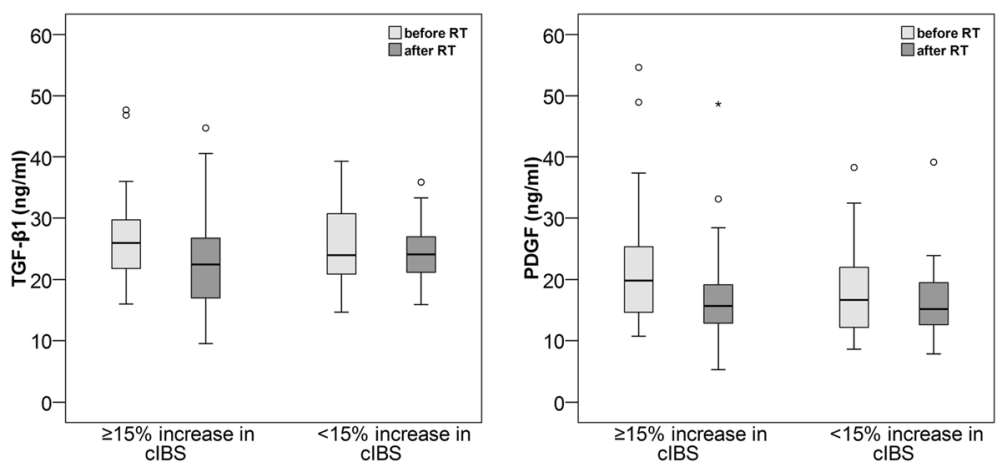

Fig. 4 TGF $\beta-1$ and PDGF levels decreased significantly in patients with $\mathrm{a} \geq 15 \%$ increase in $\mathrm{CIBS}, p<0.001$ for both, but remain stable in patients with $a<15 \%$ increase in CIBS

$\mathrm{ml}$ after RT, $p<0.001$, in patients with a $\geq 15 \%$ increase in cIBS. There was no significant change in PDGF levels in patients with $\mathrm{a}<15 \%$ increase in cIBS, with a median PDGF of 16.6 (IQR 11.7-22.6) before RT and 15.2 (IQR 12.6-19.8) after RT, $p=0.053$. The baseline PDGF level tended to be higher in those with $\mathrm{a} \geq 15 \%$ increase than in those with $\mathrm{a}<15 \%$ increase in cIBS, $p=0.050$. The change in PDGF did not correlate with the change in cIBS (Additional file 4: Table S4). In a multivariable logistic regression analysis change in PDGF remained significant, OR 0.88 (95\% CI 0.78-0.99), when age, hypertension and mean heart dose were included in the model (Additional file 6: Table S6).

The radiation doses, especially those to the left side of the heart and to the ipsilateral lung, were higher in those with $\mathrm{a} \geq 15 \%$ increase in cIBS than those with a $<15 \%$ increase in cIBS. Table 3 presents a detailed depiction of the radiation doses.

\section{Discussion}

In this study, we demonstrated the behavior of serum TGF- $\beta 1$ and PDGF during adjuvant RT for breast cancer. A small decline was observed in all patients, but the decline was most pronounced in patients with worsening cardiac function and structural changes observed in echocardiography. We also found a strong correlation between baseline TGF- $\beta 1$ and PDGF levels and the change in TGF- $\beta 1$ and PDGF levels during RT. This correlation is probably explained by the same origin of both cytokines, which are produced by macrophages, although TGF- $\beta 1$ is additionally produced by endothelial and mesenchymal cells $[1,2]$. This result suggests that the behavior of both cytokines depict the same phenomenon during adjuvant $\mathrm{RT}$ for breast cancer. The time from surgery to RT did not affect TGF- $\beta 1$ and PDGF levels and change in these levels. This is probably because the wound was healed by the time RT started and the half-life of TGF- $\beta 1$ and PDGF in serum is short [21].
Transforming growth factor-beta 1 and cardiac function It is generally accepted that TGF- $\beta 1$ is a pro-fibrotic cytokine that initiates fibrosis in response to RT [1, 2]. Additionally, it plays a role in cardiac remodeling after myocardial infarction [3]. Earlier studies have shown that an increase in TGF- $\beta 1$ during RT for non-small cell lung cancer is likely to be predictive for the development of radiation pneumonitis [6]. However, some studies do not confirm this finding, and in patients who do not develop radiation pneumonitis, a decrease in TGF- $\beta 1$ levels is seen [22,23]. In lung cancer, this decline is thought to represent a decrease in production of TGF- $\beta 1$ by tumor cells. However, this explanation probably does not explain the decline in TGF- $\beta 1$ in our study since our patients underwent breast conserving surgery or mastectomy and the likelihood of macroscopic tumor residual is extremely small.

The dynamics of TGF- $\beta 1$ during adjuvant RT for breast cancer have not been previously reported; however, two studies found that an increased TGF- $\beta 1$ level before RT was predictive of fibrosis of the breast $[4,5]$. Neither of these studies reported the behavior of TGF- $\beta 1$ during RT. In our patients with a $15 \%$ decline in TAPSE, the baseline TGF- $\beta 1$ level was higher than that in patients without the decline, indicating an association between high TGF- $\beta 1$ levels and right ventricular dysfunction induced by RT.

TGF- $\beta 1$ also seems to be a marker of radiosensitivity. A decrease in TGF- $\beta 1$ levels during RT is associated with a positive response to RT [24]. Additionally, in vitro experiments suggest that blockade of TGF- $\beta 1$ during RT for non-small cell lung cancer and breast cancer increases radiosensitivity $[25,26]$. Therefore, increased TGF- $\beta 1$ levels seem to be a marker for both radioresistance and radiosensitivity, depending on the tissue in question. As the association of TGF- $\beta 1$ and echocardiographic has not been studied during RT, we present a novel finding. Levels of TGF- $\beta 1$ decreased significantly in patients with a decline in TAPSE and an increase in cIBS. TAPSE is in wide 
Table 3 Radiation doses according to the change in cIBS

\begin{tabular}{|c|c|c|c|}
\hline \multirow[t]{2}{*}{ Structure } & $\geq 15 \%$ increase in clBS $(n=29)$ & $<15 \%$ increase in CIBS $(n=35)$ & \\
\hline & $\mathrm{Md}(\mathrm{QQR})$ & $\mathrm{Md}(\mathrm{QQR})$ & $p$ \\
\hline \multicolumn{4}{|l|}{ Heart } \\
\hline Dmean (Gy) & $3.4(1.1-4.2)$ & $1.6(0.8-2.7)$ & 0.011 \\
\hline Dmax (Gy) & $47.2(15.0-48.8)$ & $44.5(6.4-47.1)$ & 0.068 \\
\hline V45 (\%) & $0.5(0-1.7)$ & $0(0-0.4)$ & 0.025 \\
\hline V20 (\%) & $4.4(0-6.2)$ & $1.1(0-2.4)$ & 0.005 \\
\hline \multicolumn{4}{|l|}{ LAD } \\
\hline Dmean (Gy) & $22.9(2.3-27.3)$ & $7.3(0.4-18.0)$ & 0.042 \\
\hline Dmax (Gy) & $45.9(5.3-46.8)$ & $36.3(0.6-45.3)$ & 0.040 \\
\hline V45 (\%) & $0.4(0-13.9)$ & $0(0-0.3)$ & 0.008 \\
\hline V20 (\%) & $42.7(0-68.7)$ & $8.9(0-38.4)$ & 0.041 \\
\hline \multicolumn{4}{|l|}{ Left ventricle } \\
\hline Dmean (Gy) & $4.9(1.2-7.0)$ & $2.3(0.2-3.8)$ & 0.023 \\
\hline Dmax (Gy) & $45.8(9.0-47.8)$ & $41.7(0.7-45.9)$ & 0.080 \\
\hline V45 (\%) & $0.1(0-2.9)$ & $0(0-0.2)$ & 0.006 \\
\hline V20 (\%) & $6.7(0-10.4)$ & $1.3(0-4.7)$ & 0.021 \\
\hline V10 (\%) & $9.0(0-15.0)$ & $3.0(0-6.5)$ & 0.006 \\
\hline \multicolumn{4}{|c|}{ Right ventricle $(n=49)$} \\
\hline Dmean (Gy) & $2.4(1.1-3.1)$ & $1.5(0.9-2.3)$ & 0.074 \\
\hline $\operatorname{Dmax}(\mathrm{Gy})$ & $29.6(3.6-44.0)$ & $8.1(3.0-39.3)$ & 0.189 \\
\hline V45 (\%) & $0(0-0)$ & $0(0-0)$ & 0.150 \\
\hline V20 (\%) & $0.1(0-2.7)$ & $0(0-0.4)$ & 0.053 \\
\hline V10 (\%) & $0.9(0-6.5)$ & $0(0-1.4)$ & 0.019 \\
\hline \multicolumn{4}{|l|}{ Lung } \\
\hline Dmean (Gy) & $8.2(7.6-9.6)$ & $6.8(5.5-8.2)$ & 0.001 \\
\hline Dmax (Gy) & $50.1(47.9-56.7)$ & $47.5(46.4-49.7)$ & 0.009 \\
\hline
\end{tabular}

$M d$ median, IQR interquartile range, Dmean mean radiation dose to the structure, Dmax maximum radiation dose within the structure, $V 45$ percentage of the structure volume receiving $45 \mathrm{~Gy}$ of radiation, V20 percentage of the structure volume receiving $20 \mathrm{~Gy}$ of radiation, V10 percentage of the structure volume receiving $10 \mathrm{~Gy}$ of radiation, $L A D$ left anterior descending coronary artery

clinical use as a reliable measurement of the right ventricular function, and a decline in TAPSE correlates with poor cardiac prognosis in many patient groups [17, 20]. Myocardial reflectivity can be determined with off-line analysis of the echocardiography acquisition (cIBS). Even though the exact basis for the changes in cIBS are not completely understood, an increase in cIBS presents changes in three-dimensional myocardial structure due to factors such as tissue edema or interstitial fibrosis [27].

In studies of cardiac function after an experimental myocardial infarction in mice, blockade of TGF- $\beta 1$ by an antibody increased mortality and left ventricular dilatation [28]. Another study concluded that early inhibition of TGF $\beta-1$ was detrimental and that later inhibition was beneficial to the cardiac function of mice after an MI, which indicates that the role of TGF $\beta-1$ may be different in various phases of the healing process [29]. In obese, hypertensive patients, an abundance of circulating TGF- $\beta 1$ is associated with left ventricular filling abnormalities [30]. As concluded by a review conducted by Bujak, the role of TGF- $\beta 1$ after an MI remains elusive [3].

\section{Platelet-derived growth factor and cardiac function}

PDGF consists of two linked chains, designated A, B, C or D. It can be assembled as a hetero- or homodimer [8]. We measured the heterodimer PDGF-AB and found that RT induced a decrease in PDGF that was associated with a decrease in TAPSE and an increase in cIBS. The role of PDGF in long-term adverse effects of RT is not as extensively studied as is the role of TGF $\beta-1$. During RT, PDGF levels were decreased in non-Hodgkin lymphoma patients with varying RT sites, some with preceding chemotherapy and some without [9]. In patients receiving chemotherapy and RT, PDGF and TGF- $\beta 1$ levels remained unchanged [10]. Because the sites of $\mathrm{RT}$ varied, some patients had intact tumors and some patients had 
chemotherapy that also may influence cytokine levels, indicating that the studies were quite different from our study.

The effect of PDGF has also been studied through inhibition of the PDGF receptor. In mice, treatment with a PDGF receptor tyrosine kinase inhibitor, imatinib, attenuated the development of lung and skin fibrosis [11, 31]. The function of PDGF in cardiac tissue remains elusive, as blockade of PDGF receptor improved cardiac function [32], but injection of exogenous PDGF-AB or PDGF-BB improved heart function after an MI [33-35].

\section{Echocardiographic changes associate with radiation doses} In our earlier study, we reported changes in TAPSE during RT of left-sided breast cancer patients but found no association with radiation doses [19]. In this study, only patients with available serum samples were included. We found that patients with left-sided breast cancer that had $\mathrm{a} \geq 15 \%$ decline in TAPSE had higher radiation doses to the whole heart, the left ventricle and the LAD than those with $\mathrm{a}<15 \%$ decline in TAPSE. There were even more differences in the radiation doses to the whole heart or parts of the heart when patients were grouped according to $\geq 15 \%$ and $<15 \%$ increases in cIBS. An increase in cIBS represents an increase in the reflectivity of the cardiac tissue, probably due to structural changes caused by RT-induced inflammation. TAPSE is a parameter depicting longitudinal function of the right ventricle. Its decrease may portray inflammatory changes because the thinness of the right ventricle makes it more sensitive to RT-induced changes [19].

\section{Study limitations}

The limitations to our study are that the population is rather small and the follow-up time is very short, as we only studied the changes that occurred during adjuvant RT. At this stage, we do not know if the echocardiographic changes are permanent or if they are associated with the development of fibrosis, which is thought to be responsible for the increased risk of cardiac morbidity after irradiation of the heart [36]. Thus, longer follow-up times are needed to determine whether the behavior of TGF- $\beta 1$ and PDGF during adjuvant RT depict permanent damage to the heart.

\section{Conclusion}

In this study, we demonstrated that RT induces a decrease in TGF- $\beta 1$ and PDGF levels in accordance with worsening cardiac function and structural changes, namely, a decrease in TAPSE and an increase in cIBS. Additionally, higher baseline TGF- $\beta 1$ and PDGF levels were associated with a decrease in TAPSE, possibly indicating a higher susceptibility to RT-induced cardiac changes. Decreases in TGF- $\beta 1$ and PDGF levels and the association of these cytokines with echocardiographic changes could depict increased sensitivity of the heart to the effects of radiation. These novel findings are preliminary and need to be confirmed by more studies and longer follow-up, as serum biomarkers are an attractive, minimally invasive and easily available option to identify RT patients in need of closer cardiological follow-up.

\section{Additional files}

\begin{abstract}
Additional file 1: Table S1. Spearman's correlation coefficients. RT radiotherapy, TFG $\beta$ transforming growth factor, PDGF platelet derived growth factor (DOCX $18 \mathrm{~kb}$ )
\end{abstract}

Additional file 2: Table S2. Spearman's correlation coefficient between changes in TFG- $\beta 1$ and PDGF and radiation doses. Dmean, mean radiation dose to the structure; Dmax, maximum radiation dose within the structure; V45 percentage of the structure volume receiving 45 Gy of radiation; V20, percentage of the structure volume receiving $20 \mathrm{~Gy}$ of radiation; V10, percentage of the structure volume receiving $10 \mathrm{~Gy}$ of radiation; $L A D$, left anterior descending coronary artery. (DOCX $18 \mathrm{~kb}$ )

Additional file 3: Table S3. Baseline characteristic according to change in TAPSE. TAPSE, tricuspid annular plane systolic excursion; BMI, body mass index; bc, breast cancer; Hypertension, use of hypertension medication; ASA, low dose acetylsalicylic acid; Diabetes, use of diabetes medication; ACE angiotensin converting enzyme inhibitor; $A R B$, angiotensin II receptor blocker; $A$ l aromatase inhibitor use. (DOCX 18 kb)

Additional file 4: Table S4. Spearman's correlation coefficient between changes in TFG- $\beta 1$, PDGF, TAPSE and cIBS. TFG- $\beta$ 1, transforming growth factor beta 1; PDGF, platelet derived growth factor; TAPSE, tricuspid annular plane systolic excursion; $C I B S$, pericardium calibrated integrated backscatter. (DOCX $17 \mathrm{~kb}$ )

Additional file 5: Table S5. Multivariable logistic regression analysis with change $<15 \%$ or $\geq 15 \%$ in TAPSE and cIBS. TAPSE, tricuspid annular plane systolic excursion; CIBS, pericardium calibrated integrated backscatter; TFG$\beta 1$, transforming growth factor beta 1 (DOCX $18 \mathrm{~kb}$ )

Additional file 6: Table S6. Multivariable logistic regression analysis with change $<15 \%$ or $\geq 15 \%$ in TAPSE and CIBS. TAPSE, tricuspid annular plane systolic excursion; CIBS, pericardium calibrated integrated backscatter; PDGF, platelet derived growth factor. (DOCX $18 \mathrm{~kb}$ )

Additional file 7: Table S7. Baseline characteristic according to change in CIBS. CIBS, pericardium calibrated integrated backscatter; BMI, body mass index; bc, breast cancer; Hypertension, use of hypertension medication; ASA, low dose acetylsalicylic acid; Diabetes, use of diabetes medication; ACE angiotensin converting enzyme inhibitor; $A R B$, angiotensin II receptor blocker; $A$ l aromatase inhibitor use. (DOCX 18 kb)

\section{Abbreviations}

Al: Aromatase inhibitor; ASA: Acetylsalicylic acid; BMl: Body mass index; CIBS: Pericardium calibrated integrated backscatter; DCIS: Ductal carcinoma in situ; IQR: Interquartile range; LAD: Left descending coronary artery; MI: Myocardial infarction; PDGF: Platelet derived growth factor; PTV: Planning target volume; RT: Radiotherapy; TAPSE: Tricuspid annular plane systolic excursion; TGF- $\beta 1$ : Transforming growth factor beta 1

\section{Acknowledgements}

Ms. Terhi Salonen is warmly acknowledged for excellent technical assistance.

\section{Funding}

Financial support was provided by the Seppo Nieminen fund (150620 and 150636), the competitive state financing of the expert responsibility area of the Tampere University Hospital and the Paulo Foundation.

\section{Availability of data and materials}

The datasets used and analyzed during the current study are available from the corresponding author on reasonable request. 


\section{Authors' contributions}

HA prepared the draft of the manuscript and all other authors provided critical revisions of the content. HA, TS, ST, MH, W, PR, EM and PK contributed to the conception or design of the study. $\mathrm{MH}$ and EM were responsible for the analysis of the samples. HA and TL performed and interpreted statistical analyses. All authors read and approved the final manuscript.

\section{Ethics approval and consent to participate}

The study was approved by Tampere University hospital ethics committee (reference number: R10160) and informed consent was obtained from all participants.

\section{Consent for publication}

Not applicable.

\section{Competing interests}

The authors declare that they have no competing interests.

\section{Publisher's Note}

Springer Nature remains neutral with regard to jurisdictional claims in published maps and institutional affiliations.

\begin{abstract}
Author details
${ }^{1}$ Faculty of Medicine and Life Sciences, University of Tampere, PO Box 100, 33014 Tampere, Finland. 'Department of Oncology, Tampere University Hospital, PO Box 2000, 33521 Tampere, Finland. ${ }^{3}$ Heart Hospital, Tampere University Hospital, PO Box 2000, 33521 Tampere, Finland. ${ }^{4}$ Department of Cardiology, Heart and Lung Center, Helsinki University Hospital, PO Box 340 Tampere 00029, Finland. ${ }^{5}$ Research, Development and Innovation Center, Pirkanmaa Hospital District, PO Box 2000, 33521 Tampere, Finland. ${ }^{6}$ Health Sciences, Faculty of Social Sciences, University of Tampere, PO Box 100, 33014 Tampere, Finland. ${ }^{\top} T$ The Immunopharmacology Research Group, Faculty of Medicine and Life Sciences, University of Tampere and Tampere University Hospital, PO Box 100, 33014 Tampere, Finland.
\end{abstract}

Received: 10 June 2018 Accepted: 4 October 2018

Published online: 19 October 2018

\section{References}

1. Westbury CB, Yarnold JR. Radiation fibrosis - current clinical and therapeutic perspectives. Clin Oncol. 2012;24:657-72.

2. Yarnold J, Vozenin Brotons M-C. Pathogenetic mechanisms in radiation fibrosis. Radiother Oncol. 2010;97:149-61. https://doi.org/10.1016/j.radonc. 2010.09.002

3. Bujak M, Frangogiannis $N$. The role of TGF- $\beta$ signaling in myocardial infarction and cardiac remodeling. Cardiovasc Res. 2007;74:184-95. https://doi.org/10. 1016/j.cardiores.2006.10.002.

4. Li C, Wilson PB, Levine E, Barber J, Stewart AL, Kumar S. TGF-beta1 levels in pre-treatment plasma identify breast cancer patients at risk of developing post-radiotherapy fibrosis. Int J Cancer. 1999;84:155-9.

5. Boothe DL, Coplowitz S, Greenwood E, Barney CL, Christos PJ, Parashar B, et al. Transforming growth factor $\beta-1$ (TGF- $\beta 1$ ) is a serum biomarker of radiation induced fibrosis in patients treated with Intracavitary accelerated partial breast irradiation: preliminary results of a prospective study. Int J Radiat Oncol Biol Phys. 2013;87:1030-6. https://doi.org/10.1016/j.ijrobp.2013.08.045.

6. Zhang X-J, Sun J-G, Sun J, Ming H, Wang X-X, Wu L, et al. Prediction of radiation pneumonitis in lung cancer patients: a systematic review. J Cancer Res Clin Oncol. 2012;138:2103-16. https://doi.org/10.1007/s00432-012-1284-1.

7. Scherer SD, Bauer J, Schmaus A, Neumaier C, Herskind C, Veldwijk MR, et al. TGF- $\beta 1$ is present at high levels in wound fluid from breast Cancer patients immediately post-surgery, and is not increased by intraoperative radiation therapy (IORT). PLoS One. 2016;11:e0162221. https://doi.org/10.1371/journal. pone.0162221.

8. Li M, Jendrossek V, Belka C. The role of PDGF in radiation oncology. Radiat Oncol. 2007;2:5. https://doi.org/10.1186/1748-717X-2-5.

9. Ria R, Cirulli T, Giannini T, Bambace S, Serio G, Portaluri M, et al. Serum levels of angiogenic cytokines decrease after radiotherapy in non-Hodgkin lymphomas. Clin Exp Med. 2008;8:141-5. https://doi.org/10.1007/s10238-008-0170-2.
10. Villani F, Busia A, Villani M, Vismara C, Viviani S, Bonfante V. Serum cytokine in response to chemo-radiotherapy for Hodgkin's disease. Tumori. 2008:94: 803-8. https://doi.org/10.1700/396.4659.

11. Abdollahi A, Li M, Ping G, Plathow C, Domhan S, Kiessling F, et al. Inhibition of platelet-derived growth factor signaling attenuates pulmonary fibrosis. J Exp Med. 2005;201:925-35. https://doi.org/10.1084/jem.20041393.

12. Dadrich M, Nicolay NH, Flechsig P, Bickelhaupt S, Hoeltgen L, Roeder F, et al. Combined inhibition of TGF $\beta$ and PDGF signaling attenuates radiationinduced pulmonary fibrosis. Oncoimmunology. 2016;5:e1123366. https://doi.org/10.1080/2162402X.2015.1123366.

13. Tuohinen SS, Skytta T, Virtanen V, Virtanen M, Luukkaala T, KellokumpuLehtinen $P$ - $L$, et al. Detection of radiotherapy-induced myocardial changes by ultrasound tissue characterisation in patients with breast cancer. Int J Cardiovasc Imaging. 2016;32:767-76.

14. Skytta T, Tuohinen S, Boman E, Virtanen V, Raatikainen P, Kellokumpu-Lehtinen P-L. Troponin T-release associates with cardiac radiation doses during adjuvant left-sided breast cancer radiotherapy. Radiat Oncol. 2015;10:141.

15. Lang RM, Badano LP, Mor-Avi V, Afilalo J, Armstrong A, Ernande L, et al. Recommendations for cardiac chamber quantification by echocardiography in adults: an update from the American Society of Echocardiography and the European Association of Cardiovascular Imaging. Eur Heart J Cardiovasc Imaging. 2015;16:233-70

16. Galderisi M, Henein MY, D'hooge J, Sicari R, Badano LP, Zamorano JL, et al. Recommendations of the European Association of Echocardiography: how to use echo-Doppler in clinical trials: different modalities for different purposes. Eur J Echocardiogr. 2011;12:339-53.

17. Rudski LG, Lai WW, Afilalo J, Hua L, Handschumacher MD, Chandrasekaran K et al. Guidelines for the echocardiographic assessment of the right heart in adults: a report from the American Society of Echocardiography endorsed by the European Association of Echocardiography, a registered branch of the European Society of Cardiology, and t. J Am Soc Echocardiogr. 2010;23: 685-8.

18. Nagueh SF, Appleton CP, Gillebert TC, Marino PN, Oh JK, Smiseth OA, et al. Recommendations for the evaluation of left ventricular diastolic function by echocardiography. Eur J Echocardiogr. 2009;10:165-93.

19. Tuohinen SS, Skytta T, Virtanen V, Luukkaala T, Kellokumpu-Lehtinen P-L, Raatikainen P. Early effects of adjuvant breast cancer radiotherapy on right ventricular systolic and diastolic function. Anticancer Res. 2015;35:2141-7.

20. Forfia PR, Fisher MR, Mathai SC, Housten-Harris T, Hemnes AR, Borlaug BA, et al. Tricuspid annular displacement predicts survival in pulmonary hypertension. Am J Respir Crit Care Med. 2006;174:1034-41. https://doi.org/ 10.1164/rccm.200604-5470C

21. Coffey RJ, Kost LJ, Lyons RM, Moses HL, LaRusso NF. Hepatic processing of transforming growth factor beta in the rat. Uptake, metabolism, and biliary excretion. J Clin Invest. 1987;80:750-7. https://doi.org/10.1172/JCI113130.

22. De Jaeger $K$, Seppenwoolde $Y$, Kampinga HH, Boersma LJ, Belderbos JSA, Lebesque JV. Significance of plasma transforming growth factor-beta levels in radiotherapy for non-small-cell lung cancer. Int J Radiat Oncol Biol Phys. 2004:58:1378-87. https://doi.org/10.1016/j.ijrobp.2003.09.078.

23. Novakova-Jiresova A, Van Gameren MM, Coppes RP, Kampinga HH, Groen HJM. Transforming growth factor-beta plasma dynamics and post-irradiation lung injury in lung cancer patients. Radiother Oncol. 2004;71:183-9. https:// doi.org/10.1016/j.radonc.2004.01.019.

24. Fu Z-Z, Gu T, Fu B-H, Hua H-X, Yang S, Zhang Y-Q, et al. Relationship of serum levels of VEGF and TGF- $\beta 1$ with radiosensitivity of elderly patients with unresectable non-small cell lung cancer. Tumor Biol. 2014;35:4785-9. https://doi.org/10.1007/s13277-014-1628-3.

25. Bouquet F, Pal A, Pilones KA, Demaria S, Hann B, Akhurst RJ, et al. TGF 1 inhibition increases the Radiosensitivity of breast Cancer cells in vitro and promotes tumor control by radiation in vivo. Clin Cancer Res. 2011;17:675465. https://doi.org/10.1158/1078-0432.CCR-11-0544.

26. Du S, Bouquet S, Lo C-H, Pellicciotta I, Bolourchi S, Parry R, et al. Attenuation of the DNA damage response by transforming growth factor-Beta inhibitors enhances radiation sensitivity of non-small-cell lung Cancer cells in vitro and in vivo. Int J Radiat Oncol. 2015;91:91-9. https://doi.org/10.1016/j.jirobp. 2014.09.026.

27. Mor-Avi V, Lang RM, Badano LP, Belohlavek M, Cardim NM, Derumeaux G, et al Current and evolving echocardiographic techniques for the quantitative evaluation of cardiac mechanics: ASE/EAE consensus statement on methodology and indications endorsed by the Japanese Society of Echocardiography. Eur J Echocardiogr. 2011;12:167-205. https://doi.org/10.1093/ejechocard/jer021. 
28. Frantz S, Hu K, Adamek A, Wolf J, Sallam A, KG Maier S, et al. Transforming growth factor beta inhibition increases mortality and left ventricular dilatation after myocardial infarction. Basic Res Cardiol. 2008;103:485-92. https://doi.org/10.1007/s00395-008-0739-7.

29. Ikeuchi M, Tsutsui H, Shiomi T, Matsusaka H, Matsushima S, Wen J, et al. Inhibition of TGF-beta signaling exacerbates early cardiac dysfunction but prevents late remodeling after infarction. Cardiovasc Res. 2004;64:526-35. https://doi.org/10.1016/..cardiores.2004.07.017.

30. Parrinello G, Licata A, Colomba D, Di Chiara T, Argano C, Bologna P, et al. Left ventricular filling abnormalities and obesity-associated hypertension: relationship with overproduction of circulating transforming growth factor B1. J Hum Hypertens. 2005;19:543-50. https://doi.org/10.1038/sj.jhh.1001864.

31. Horton JA, Chung EJ, Hudak KE, Sowers A, Thetford A, White AO, et al. Inhibition of radiation-induced skin fibrosis with imatinib. Int J Radiat Biol. 2013:89:162-70. https://doi.org/10.3109/09553002.2013.741281.

32. Liu C, Zhao W, Meng W, Zhao T, Chen Y, Ahokas RA, et al. Platelet-derived growth factor blockade on cardiac remodeling following infarction. Mol Cell Biochem. 2014;397:295-304. https://doi.org/10.1007/s11010-014-2197-x.

33. Zheng J, Shin JH, Xaymardan M, Chin A, Duignan I, Hong MK, et al. Plateletderived growth factor improves cardiac function in a rodent myocardial infarction model. Coron Artery Dis. 2004;15:59-64.

34. Hsieh PCH, MacGillivray C, Gannon J, Cruz FU, Lee RT. Local controlled Intramyocardial delivery of platelet-derived growth factor improves Postinfarction ventricular function without pulmonary toxicity. Circulation. 2006;114:637-44. https://doi.org/10.1161/CIRCULATIONAHA.106.639831.

35. Chin A, Zheng J, Duignan I, Edelberg JM. PDGF-AB-based functional cardioprotection of the aging rat heart. Exp Gerontol. 2006;41:63-8. https://doi.org/10.1016/j.exger.2005.10.012.

36. Sardaro A, Petruzzelli MF, D'Errico MP, Grimaldi L, Pili G, Portaluri M. Radiationinduced cardiac damage in early left breast cancer patients: risk factors, biological mechanisms, radiobiology, and dosimetric constraints. Radiother Oncol. 2012;103:133-42. https://doi.org/10.1016/.jradonc.2012.02.008.

Ready to submit your research? Choose BMC and benefit from:

- fast, convenient online submission

- thorough peer review by experienced researchers in your field

- rapid publication on acceptance

- support for research data, including large and complex data types

- gold Open Access which fosters wider collaboration and increased citations

- maximum visibility for your research: over $100 \mathrm{M}$ website views per year

At $\mathrm{BMC}$, research is always in progress.

Learn more biomedcentral.com/submissions 